\title{
Folliculosebaceous cystic hamartoma
}

\section{Leila Bouhaja ${ }^{1}$, Meriam Jones ${ }^{2}$, Soumaya Rammeh ${ }^{1}$}

\author{
${ }^{1}$ Department of Pathology, Charles Nicolle Hospital, Tunis, Tunisia, ${ }^{2}$ Department of Dermatology, Charles Nicolle Hospital, \\ Tunis, Tunisia
}

Corresponding author: Dr. Leila Bouhajja, E-mail: bouhaja.leila@gmail.com

Sir,

We report a 34 year-old man, with no past medical history, who presented with a 2-year history of a nodule on the nose. At physical examination the lesion was firm, pedunculated, and flesh-colored with a smooth surface. Clinically, the diagnosis of adnexal tumor was suggested and a surgical resection of the lesion was performed. Grossly, the tumor was firm pedunculated measuring $6 \mathrm{~mm}$ in size, raising the epidermis (Fig. 1). Histological examination showed a well-circumscribed lesion of the dermis composed of numerous sebaceous follicles structures. Some were dilated forming cysts and connected directly to the epidermis (Fig. 2). These epithelial structures were surrounded by a fibrohyalin stroma combined with a fibrous component containing adipocytes (Fig. 3). These features were reminiscent with the diagnosis of folliculosebaceous cystic hamartoma. At 10 months of follow-up, the patient was asymptomatic and had no recurrence.

The patient's informed consent was obtained.

Prior to the study, patient gave written consent to the examination and biopsy after having been informed about the procedure.

Folliculosebaceous cystic hamartoma (FSCH) is a rare cutaneous hamartoma composed of dilated folliculosebaceous units associated with mesenchymal elements [1]. This tumor may occur in all age groups, and females are affected more often than males [2]. Clinically, it manifests as a solitary skin-colored sessile or pedunculated nodule that is most commonly located on the face and scalp, with approximately $30 \%$ occurring in the nasal or paranasal regions. The lesion is usually less than $3 \mathrm{~cm}$ in size $[3,4]$. The

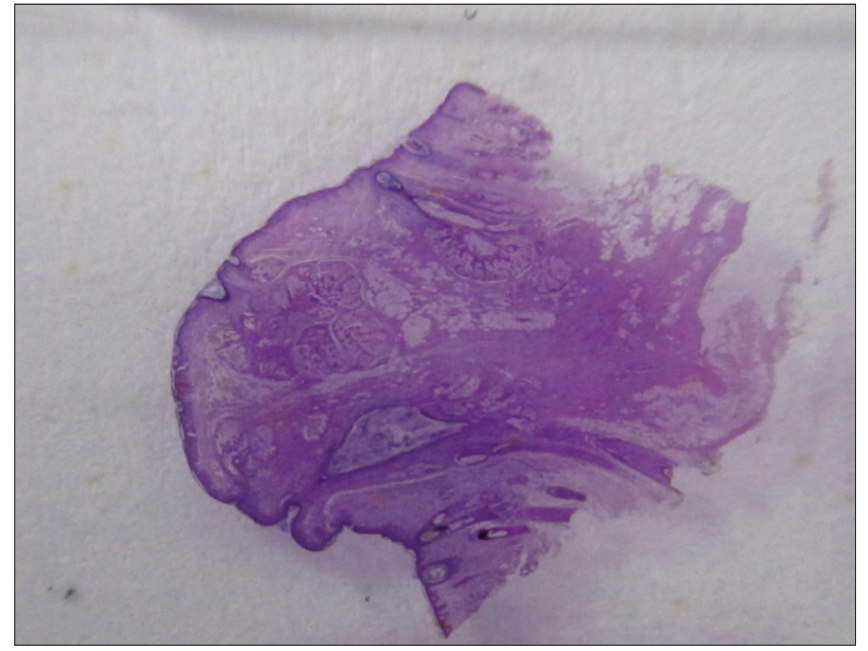

Figure 1: A slide-mounted pedunculated tumor raising the epidermis.

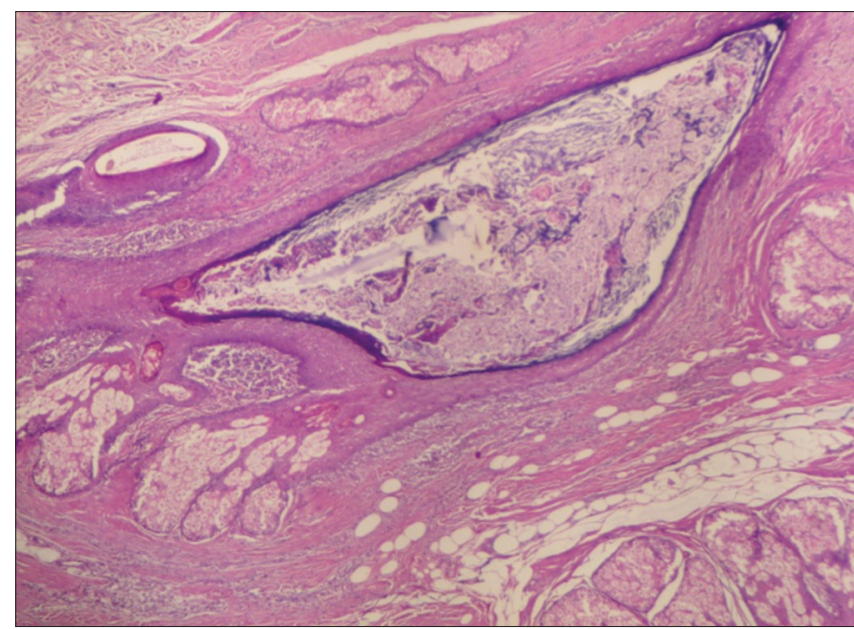

Figure 2: Dilated follicular cyst structure with infundibular keratinization surrounded by numerous sebaceous lobules in the dermis (HEx100).

main differential diagnoses are nevus lipomatosus superficialis or "sebaceous" trichofolliculoma which may include sebaceous glands but no central cyst [5]. FSCH can be readily identified by the presence of

\footnotetext{
How to cite this article: Bouhaja L, Jones M, Rammeh S. Folliculosebaceous cystic hamartoma. Our Dermatol Online. 2016;7(4):477-478.

Submission: 18.03 .2016 ; Acceptance: 13.06 .2016

DOI:10.7241/ourd.20164.130
} 


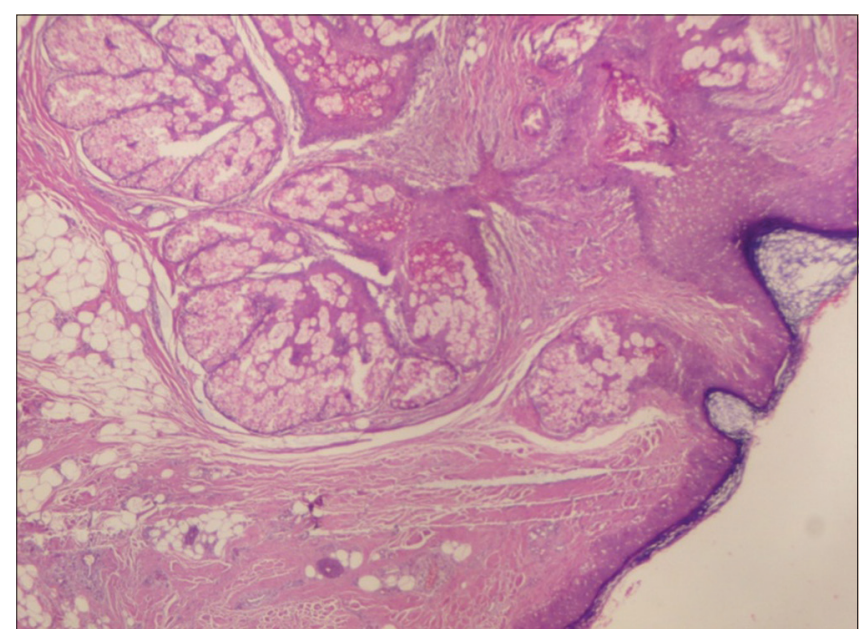

Figure 3: Stroma surrounding the folliculosebaceous structures consisting of collagen bundles interspersed with adipocytes (HEx40).

adipocytes and a fibrous stroma. The treatment consists of total excision of the tumor.

\section{Consent}

The examination of the patient was conducted according to the Declaration of Helsinki principles.
Written informed consent was obtained from the patient for publication of this article.

\section{REFERENCES}

1. Osipov VO, Vincent P, Packer AM., Oliver GF. Folliculosebaceous cystic hamartoma of the ear and periauricular skin. Austral J Dermatol. 2012;53:e8-e9.

2. Ansai S, Kimura T, Kawana S. A clinicopathologic study of folliculosebaceous cystic hamartoma. Am J Dermatopathol. 2010;32:815-20.

3. Watanabe-Okada E, Kurihara Y, Miyakawa S, Tanaka M. Dermatoscopy of folliculosebaceous cystic hamartoma. Dermatol Pract Concept. 2014;4:47-9.

4. Nguyen CM, Skupsky H, Cassarino D. Folliculosebaceous Cystic Hamartoma With Spindle Cell Lipoma-Like Stromal Features. Am J Dermatopathol. 2015;37:e140-2

5. Merklen-Djafri C, Batard M.-L, Guillaume J-C, Kleinclauss I, Cribier B. Folliculosebaceous cystic hamartoma: Anatomo-clinical study. Ann Dermatol Venereol. 2012;139:23-30.

Copyright by Leila Bouhaja, et al. This is an open access article distributed under the terms of the Creative Commons Attribution License, which permits unrestricted use, distribution, and reproduction in any medium, provided the original author and source are credited.

Source of Support: Nil, Conflict of Interest: None declared. 